\title{
The Incentives and their effect on performance "Study on the College of Law Barak"(Libya)
}

\author{
Arrasheid Abduallah Alarrasheid ${ }^{1}$, Dr. Reena Mehta ${ }^{2}$ \\ ('PhD student,SHIATS-DU,Allahabad,U.P.,India) \\ ( ${ }^{2}$ Dr. Reena ,SHIATS-DU,Allahabad,U.P.,India)
}

\begin{abstract}
Title of this study is" Incentives and their effect on performance " in the community of the study focuses on the staff in the College of Law Barak. The total number of employees (170) and by table (Kregcie and Morgan, 1970) the sample study reached (89) numbers, and the data collected by the questionnaire were analyzed by statistical package for social sciences SPSS. The study found out the results indicate a meager role of the employees in the process of decision-making. Moreover, chiefs pay only scant attention to the employee's suggestions, which negatively affect their drive.In addition, promotion chances are in no way related to the performance record.Most of the employees complain from the low level of bonuses.
\end{abstract}

Keyword: Incentives, performance, statisticalSPSS.

\section{Introduction}

Human resource considered as the most inconsistent variable in the production process as he has feelings and needs that he expresses in different ways, and which in turn, affect performance in organizations. Moreover, interests, commitment, and seriousness vary from one person to another and from one period to another as a result of the difference in motives and needs. Thus, incentives have a great role in motivating workers.Incentives is an interesting concept. What motivates one person may not necessarily motivate someone else. Now, back in the olden days, people were motivated by sheer survival. If you think about it, back in the day of the settlers or even as far back as the cavemen coming out of the cave, the motivation was to eat and have shelter just to survive.Over the years that has obviously changed and companies have come up with ways to motivate individuals. We will talk about motivation in this lesson and identify some motivational or performance incentive programs.

\section{Statement Of The Problem}

Motivation is one of the most important concepts of psychology and very vital for managers who direct the growth of their subordinates towards worthwhile goals. Administration is working hard to improve the performance of employees and push them toward goals Plotted possible and legitimate means all, and no doubt that the relationship between the stimulus The performance is a positive relationship, where paid workers an incentive to increase the efforts that Exerted factor, which reflected positively on the performance levels of the facility. The desire Factor in getting the rewards as an incentive behind his positive behavior to improve the performance. I observation the performance of employees in the College of Law Barak have low levels, I thought the bad motivation is the problems affect the performance of employees in the College of Law Barak. So I would like to carry out a field study, in order to specify how far Incentives and their can effect on performance the problem of study can be illustrated in the following question:-

How far Incentives and their can effect on performance of employees in the College of Law Barak?

\section{Objectives Of Study}

This study aimed to get to know the reality impact of these incentives on the overall performance survey, and what are the most important incentives Paid workers and affect their desires in order to improve their performance in the field of employment, as well It aims to identify the degree of difference between the sample in the performance of individuals To work depending on the variables under consideration, such as experience, educational qualification, marital status, Training courses, Age.

\section{Important Of Study}

All individual have a variety of needs in any organization and until it is motivating employees the motivation should improve the analysis of these needs, and to identify the most important needs for individuals, and then work on the development and preparation of returns and bonus system commensurate with her. And the greater the degree of harmonization and compatibility between the system and the returns between the needs Increased motivation and productivity. The administration always trying to identify the behaviors of individuals andattitudes, and is influencing the trends And the actions of members of the organization in any organization, stir desires and motivations to work. 


\section{Methodology Of Study}

The community of study is consisted of the College of Law Barak. Barak is located in the south of Libya, the population of Barak is around "56075" .The total off the working staff is "225" and in accordance with table "1970" by "Kregcic \& Morgan " the sample number reached "100" of the study community, the study sample choose by stratified random sample cause I would like give same chance for all community to showed.

1.Analysis data related with material incentives more impetus for employees to improve their work and quality than moral incentives.

About this paragraph, I tried to discuss the ten types of incentives that are believed that are directly related to the performance of the conditions of work and asked respondents about the degree of importance Every incentive for them to improve their performance and received answers as in the table(1).

Table (1). Material incentives more impetus for employees to improve their work and quality than moral incentives

\begin{tabular}{|l|l|l|l|}
\hline types of incentives & Average & $\begin{array}{l}\text { Standard } \\
\text { deviation }\end{array}$ & $\begin{array}{l}\text { Degree of } \\
\text { Importance }\end{array}$ \\
\hline Relationship with colleagues & 3.26 & 1.553 & higher \\
\hline RelationshipwithPresidents & 3.66 & 1.768 & higher \\
\hline jobstability & 3.88 & 1.637 & higher \\
\hline The importance of working & 3.11 & 1.878 & meddle \\
\hline Appreciation of efforts & 3.10 & 1.228 & meddle \\
\hline Progress and advancement of work & 3.00 & 0.983 & meddle \\
\hline Powers granted & 2.55 & 1.676 & lower \\
\hline Services and benefits & 2.10 & 1.767 & lower \\
\hline Wages and material incentive & 226 & 1.553 & lower \\
\hline
\end{tabular}

Table (1) shows that although social relations prevail betweenColleagues with each other, as well as with their superiors, are an important incentive to payWho are largely working to improve their work in which they are stable, given the importanceThey get it from estimates of their efforts, but workers complain of a declineOpportunities for progress, lack of authority, and various services and benefitsThey receive very little and do not meet the needs of the workers, so they are not motivatedThis may be due to the possibility of the autocratic approachAdministrative corridors and central management policy.

Through the above rejected the first hypothesis "that material incentives are more prompting workers to improve their work and quality of moral incentives".

2. Analysis data related withExtent of application of the incentive system and its impact on performance.

Extent of application of the incentive system and its impact on performance And to validate the second hypothesis on the application of incentive system Exploration and production its impact on performance, has been divided The third part of the questionnaire is divided into six axes, which revolves around the importance of work and appreciation Respect, progress and advancement, supervisory methods, work incentives, overall performance. The These axes included a number of paragraphs whose computational averages were calculated, Standard deviations, percentages of approval, as well as the overall average For each of the axes mentioned Table (2).

Table (2). Application of the incentive system and its impact on performance

\begin{tabular}{|l|l|l|l|l|}
\hline types of incentives & Paragraph & Average & $\begin{array}{l}\text { Standard } \\
\text { deviation }\end{array}$ & $\begin{array}{l}\text { Degree of } \\
\text { Importance }\end{array}$ \\
\hline \multirow{5}{*}{$\begin{array}{l}\text { The importance of } \\
\text { work }\end{array}$} & $\begin{array}{l}\text { Your achievement of work motivates you to improve } \\
\text { performance. }\end{array}$ & 3.99 & 0.553 & higher \\
\cline { 2 - 5 } & $\begin{array}{l}\text { Your current job makes you feel proud and makes you } \\
\text { mastered it. }\end{array}$ & 1.66 & 0.768 & lower \\
\cline { 2 - 6 } & $\begin{array}{l}\text { Your love for the current job drives you to work } \\
\text { Enthusiasm. }\end{array}$ & 3.02 & 1.637 & middle \\
\hline Business incentives & The reward increases my activity at work. & 2.11 & 1.856 & lower \\
\cline { 2 - 5 } & The wages of his work are enough for me. & 2.34 & 1.278 & lower \\
\cline { 2 - 5 } & $\begin{array}{l}\text { The incentives provided to employees depend on } \\
\text { Performance reports. }\end{array}$ & 2.78 & 0.998 \\
\hline
\end{tabular}

\subsection{The importance of work:-}

The design of business or jobs appropriately makes the work important Great in stimulating the activity and enthusiasm of the workers, the design of the studied and effective function Makes achievement a potential catalyst in the world, and raises the spirit of challenge and creativity he has, can For his work to feel proud and proud, and push him to master it and then achieve the objectives of the Organization Efficiently and effectively. Back to the paragraphs of this axis has got the first paragraph about Satisfaction with the completion 
of the current work and its role in motivating the employees, to the degree of approvalA large staff of the Yemeni Oil Exploration and Production Authority, with an average of 3,537 The approval rate reached (70.47\%) which indicates a good achievement and a good desire to do With current business, this motivates and drives employees to improve their performance. On the second paragraph Whether the employees' duties make them feel proud or proud of their current work, And increased their proficiency to their roles required of them, it was the arithmetic mean of this paragraphand by $(68.54 \%)$, which means that the degree of approval is relatively low, This requires additional management efforts to improve the employability of diverse competencies In order to exploit these energies to enhance the convictions of the workers in their duties. In paragraph the third of this axis is about the extent to which employees love their work and whether they are paid for their duties with greater enthusiasm, this paragraph received a high approval rate of (76.3).

\subsection{Business incentives:-}

Incentives in business organizations rely on performance reports the perpetual glory is given a reward for its excellence, and the punishment is punished, or it is denied of the tender, to increase the rush of the first and his gifts, and avoid the second shortness and correct from His mistakes. In this way, the administration will confront any deviations that appear in the fields of business. While regarding the paragraphs of this theme, the respondents' opinions on whether the bonus was paid were questioned they receive in return for outstanding performance increases their activity, the results of the survey showed that The approval score was low at $(66.82 \%)$ and its mean $(3,341)$ There is a conviction among a large proportion of those in the field of research that the rewards are They receive influence, reflect on their morale, and push them to get the job done better. In the next paragraph, which explains the status of wages and salaries received by workers and so on if this wage is sufficient to satisfy his needs, and represents his conviction, he reached the average $(\% 1,622)$ and the degree of approval is absent, reaching (32.44This means that there is no conviction among workers in this vital sector of wages Reflected negatively on their satisfaction, and then on their performance, and salaries are because of their weakness A negative factor in progress, or, in other words, a major cause of inadequacy and lack Motivation at work. The paragraph discussing incentives for employees is based on Appropriate performance reports, the arithmetic average of this paragraph $(2,439)$, was The percentage of sample approval on this paragraph $(48,78 \%)$, this may be due to the incentives Provided by the administrative leadership acted for all employees, without regard to reports Performance evaluation This is what some of the sample referred to the researchers during the distribution and collection Questionnaires Here the incentives are compensation for the noticeable lack of salaries as a result Rising costs of living, thereby losing incentives in the organization much of its expected impact. With regard to the outcome of this axis, the result of the approval of this $(28,51 \%)$ was the arithmetic average $(2,564)$ the approval of the labor incentives, which requires careful consideration, and within available means, of what is being done Capacity of employees serving the business interest.

Through the above-accepted second hypothesis, there is a positive relationship between the degree of application of the system of incentives and the degree of overall performance.

\section{Results And Recommendations}

The study found out the results indicate a meager role of the employees in the process of decision making. Moreover, chiefs pay only scant attention to the employee's suggestions, which negatively affect their drive. In addition, promotion chances are in no way related to the performance record. Further, most of the employees complain from the low level of bonuses. And accepted second hypothesis there is a positive relationship between the degree of application of the system of incentives and the degree of overall performance

\section{VII.Recommendations}

the study recommends activating bonuses and relating them to performance, adjusting and improving the administrative systems, adopting the promotion system, and strengthening the feeling of loyalty for the organization by getting the employees involved in the decision making process.

\section{Referenced}

[1]. Argyle M.et.al. Social Situations - Cambridge University Press - London,1991.

[2]. Boulding K. Conflict and Defense - Harper - London,1982.

[3]. Howe L.W.\& Howe M.M. Personalizing Education Hant. - New York,1995

[4]. SadrAshour, Department of Labor Force, Dar al-Nahdaal-Arabiya, Beirut, 1990.

[5]. Mayer, Department of Human Resources, Alexandria University, First Edition 2010.

[6]. Williamson, Oliver. Organization theory. Chester Barnard to the present and beyond. Oxford University Press, 1995. 